Int. J. Plant Sci. 178(4):320-329. 2017.

(c) 2017 by The University of Chicago. All rights reserved.

1058-5893/2017/17804-0006\$15.00 DOI: $10.1086 / 691144$

\title{
NEW INSIGHTS INTO THE SYSTEMATICS OF THE SCHOENOXIPHIUM CLADE (CAREX, CYPERACEAE)
}

\author{
T. Villaverde, ${ }^{1,2, *}$ E. Maguilla, ${ }^{1, *}$ M. Escudero, † J. I. Márquez-Corro, ${ }^{*}$ P. Jiménez-Mejías, $\neq$ \\ B. Gehrke,§S. Martín-Bravo, ${ }^{3, *}$ and M. Luceño ${ }^{3, *}$ \\ *Botany Area, Department of Molecular Biology and Biochemical Engineering, Universidad Pablo de Olavide, Carretera de Utrera km 1, \\ ES-41013 Seville, Spain; tDepartment of Plant Biology and Ecology, University of Seville, Reina Mercedes 6, ES-41012 Seville, \\ Spain; ¥New York Botanical Garden, 2900 Southern Boulevard, Bronx, New York 10458, USA \\ and §Johannes Gutenberg-Universität, 55122 Mainz, Germany \\ Editor: Erika Edwards
}

\begin{abstract}
Premise of research. The Schoenoxiphium clade (Carex, Cyperaceae) exhibits a high species diversity in South Africa and a complex taxonomy. Previous phylogenetic studies did not resolve the species relationships within the Schoenoxiphium clade due to the lack of informative characters in DNA markers used. Our aim is to resolve the species relationships within the Schoenoxiphium clade by adding information from more markers and more samples to information from previous studies.
\end{abstract}

Methodology. We sampled 19 out of 20 recognized species in the former genus Schoenoxiphium. Four DNA regions (two nuclear ribosomal: internal transcribed spacer, external transcribed spacer; two plastid: matK and rps16) were sequenced for 134 samples. Phylogenetic reconstruction was performed using Bayesian inference and maximum likelihood analyses.

Pivotal results. The monophyly of the Schoenoxiphium clade was confirmed. Five main clades with strong support were retrieved in congruence with a previous phylogeny. Although species relationships within these clades are still partially unresolved, our phylogeny highlights the need for the description of at least two new species in this group.

Conclusions. The monophyly of the former genus Schoenoxiphium, taken together with its morphological synapomorphies and the recent phylogenetic studies and subsequent recircumscription of the genus Carex to include all nested genera, advises the consideration of this clade as a section (Carex sect. Schoenoxiphium Baillon). Additional investigations based on genomic sequencing are needed to fully resolve the species relationships within each of the five main clades.

Keywords: phylogeny, species complex, ITS, ETS, taxonomy.

\section{Introduction}

Carex L. (Cyperaceae), with ca. 2000 species (Goetghebeur et al. 1998; Global Carex Group 2015), has an almost cosmopolitan distribution and a broad habitat range. Traditionally, the genus was included as one of five genera in the tribe Cariceae Kunth ex Dumort., together with Cymophyllus Mack. ex Britton \& A.Br. (monotypic), Kobresia Willd. (ca. 60 spp.), Schoenoxiphium Nees (ca. 20 spp.), and Uncinia Pers. (ca. 70 spp.). Although tribe Cariceae forms a monophyletic group nested in the subfamily Cyperoideae, Carex is paraphyletic, because it includes the remaining genera considered within the tribe (Waterway and Starr 2007; Muasya et al. 2008). The Global Carex Group (2015) therefore suggested a new classifi-

1 These authors contributed equally.

2 Author for correspondence; e-mail: tvilhid@gmail.com.

3 These senior authors contributed equally.

Manuscript received July 2016; revised manuscript received December 2016; electronically published March 27, 2017. cation resulting in a broader circumscription of a monophyletic genus Carex that includes all other members of the tribe.

Phylogenetic work has shown that this broader circumscribed Carex comprises three strongly supported clades (Siderostictae, Vignea, and Core Carex) and a weak to moderately supported clade, the Caricoid clade, which includes most unispicate and a few multispicate Carex species as well as the remaining genera traditionally considered within the tribe (Cymophyllus, Kobresia, Schoenoxiphium, and Uncinia; Starr et al. 1999; Yen and Olmstead 2000; Roalson et al. 2001; Waterway and Starr 2007; Waterway et al. 2009). Within the Caricoid clade, two well-supported lineages are found: the Schoenoxiphium clade, including the former genus Schoenoxiphium plus two small clades of Carex species (one containing sections Junciformes and Aciculares and the other grouping C. distachya and allies; Gehrke et al. 2010; Global Carex Group 2016), and another comprising the polyphyletic genus Kobresia, the monophyletic genus Uncinia, and several clades with mostly unispicate Carex species (Waterway et al. 2009). Morphologically, most species in the Schoenoxiphium clade present compound inflorescences 
(but unispicate in sections Junciformes and Aciculares, C. macrostyla, C. peregrina, C. pulicaris, and rarely in some individuals of a few species in the former genus Schoenoxiphiun), flattened rachilla mostly present and well developed (ciliate or aculeolate in at least some individuals of all species in the former genus Schoenoxiphium), usually leading to a male spike or a spike of spikelets, perigynia closed (utricles) to wide-mouthed (utricles with male spikes protruding or utriculiform cladoprophylls; Jiménez-Mejías et al. 2016), and three stigmas. Although this group is more or less morphologically well circumscribed (Global Carex Group 2015), its species boundaries are still weakly studied, and the previous published studies (Levyns 1945; Kukkonen 1983; Timonen 1989; Gordon-Gray 1995; Gehrke et al. 2010) included only a partial species sampling. The former genus Schoenoxiphium, a monophyletic group nested in the Schoenoxiphium clade, has about 20 species, with its center of diversity in the southeastern parts of Africa, with a few species extending their distribution to southwestern Africa, eastern Africa, Madagascar, and the Arabian Peninsula (fig. 1; Gehrke et al. 2010). Moreover, recent phylogenetic analyses have suggested a complex evolutionary history of the group due to hybridization events and/or lineage sorting (Gerhke et al. 2010). In this article, our objective is to investigate the phylogenetic relationships within the former genus Schoenoxiphium to (1) increase sampling, including all extant recognized species, or nearly so; (2) represent the full distribution range of species; (3) increase DNA region sampling; (4) improve the knowledge of species boundaries; and (5) resolve the phylogenetic backbone of the former genus Schoenoxiphium.

\section{Material and Methods}

\section{Taxon Sampling}

We have sampled 19 out of 20 of the species as recognized for the former genus Schoenoxiphium by Gordon-Gray (1995) and Kukkonen (1983, 1986; see table 1), including two previously nonsampled species (Carex schimperiana Boeck. and C. kukkoneniana Luceño \& Martín-Bravo) by Gehrke et al. (2010), as well as an expanded population sampling of the other previously sampled species. The only species that was not included in the analyses is C. chermezonii Luceño \& Martín-Bravo ( = Schoenoxiphium gracile Cherm.), because we were unable to obtain herbarium or field samples.

Outgroup taxa were selected on the basis of previous work (Gehrke et al. 2010) and included the following: C. andina, C. camptoglochin, and C. transandina in the Andina clade and C. distachya, C. macrostyla, C. peregrina, C. pulicaris, and C. oedipostyla in the Distachya clade. These species formed a monophyletic group in the cited work.

\section{DNA Extractions and Sequencing}

DNA extractions and sequencing were done following Gehrke et al. (2010). We amplified the internal transcribed spacer (ITS) region (ITS-A, ITS-4; White et al. 1990; Blattner 1999), external transcribed spacer (ETS) region (ETS-1f, 18S-R; Starr et al. 2003), a portion of the matK gene using primers mat $\mathrm{K} 2.1 \mathrm{~F}$ and matK 5R (Ford et al. 2009), and rps 16 intron using primers $r p s 16 \mathrm{~F}-r p s 16 \mathrm{R}$ (Shaw et al. 2005). Therefore, two additional DNA markers were studied (ETS and matK), different from those used by Gehrke et al. (2010; ITS, trnL-F, rps16), to try to get a better resolution of the phylogeny. Sequences were edited, automatically aligned with MUSCLE, version 3.8.31 (Edgar 2004), and manually adjusted using the program Geneious, version 6.1.7 (Biomatters, Auckland, New Zealand).

\section{Phylogenetic Analyses}

We used NCBI GenBank accessions and newly obtained sequences, for a total of 116 ITS sequences, 35 ETS, 46 matK, and 87 rps16 (see appendix). All loci were analyzed independently and in combination (albeit the missing data) using maximum likelihood (ML) and Bayesian inference (BI). ML analyses were performed using RAxML, version 7.2.6 (Stamatakis 2006), with general time reversible with gamma-distributed rate variation among sites $(\mathrm{GTR}+\mathrm{G})$ and node support assessed with 10,000 bootstrap (BS) replicates. BI analyses were executed in MrBayes, version 3.2.1 (Huelsenbeck and Ronquist 2001). The most appropriate nucleotide substitution model for each partition was chosen using the Akaike information criterion in jModeltest (Posada 2008). The Markov chain Monte Carlo search was run for five million generations with a tree sampled every 1000 generations and two simultaneous analyses started from different random trees (Nruns $=2$ ), each with four Markov chains (Nchains = 4). The first $20 \%$ of the trees were discarded from each run as the burn-in, as they were sampled before convergence to the optimal mean log likelihood plateau as retrieved from BI analyses results as implemented in Geneious, version 6.1.7. A Bayesian majority-rule consensus tree was calculated in MrBayes with posterior probability (PP) values as a measure for clade support. Trees were edited using Figtree, version 1.3.1 (http://tree.bio.ed.ac.uk/software/figtree/). Gehrke et al. (2010) showed that there is a recombinant nuclear ITS region (ITS2) shared by all species in the C. ludwigii (=S. rufum) clade and by C. camptoglochin. Therefore, we repeated our analyses excluding the ITS2 region of the C. ludwigii clade. Clades were considered strongly supported when PP was $>0.95$ and when BS was $>70$.

\section{Results}

\section{Phylogenetic Reconstruction}

The combined matrix of both nuclear and plastid DNA regions consisted in 134 samples with 2960 sites (see appendix). Selected nucleotide substitution models were GTR + G, K80+I, and GTR + G for ITS1, 5.8s, and ITS2, respectively; they were $\mathrm{GTR}+\mathrm{G}$ for ETS and matK and GTR $+\mathrm{I}+\mathrm{G}$ for $r p s 16$ (appendix). Although few topological changes were found on the individual ITS gene trees when removing the ITS 2 region of the Carex ludwigii clade, those changes in topology were not supported. Consequently, the analyses of the concatenation of all four DNA regions reported exactly the same topology with irrelevant changes in clades support.

Monophyly of former genus Schoenoxiphium was strongly supported in BI and ML analyses (1 PP; 92\% BS; fig. 2). Sister to former genus Schoenoxiphium was the C. andina clade. The 


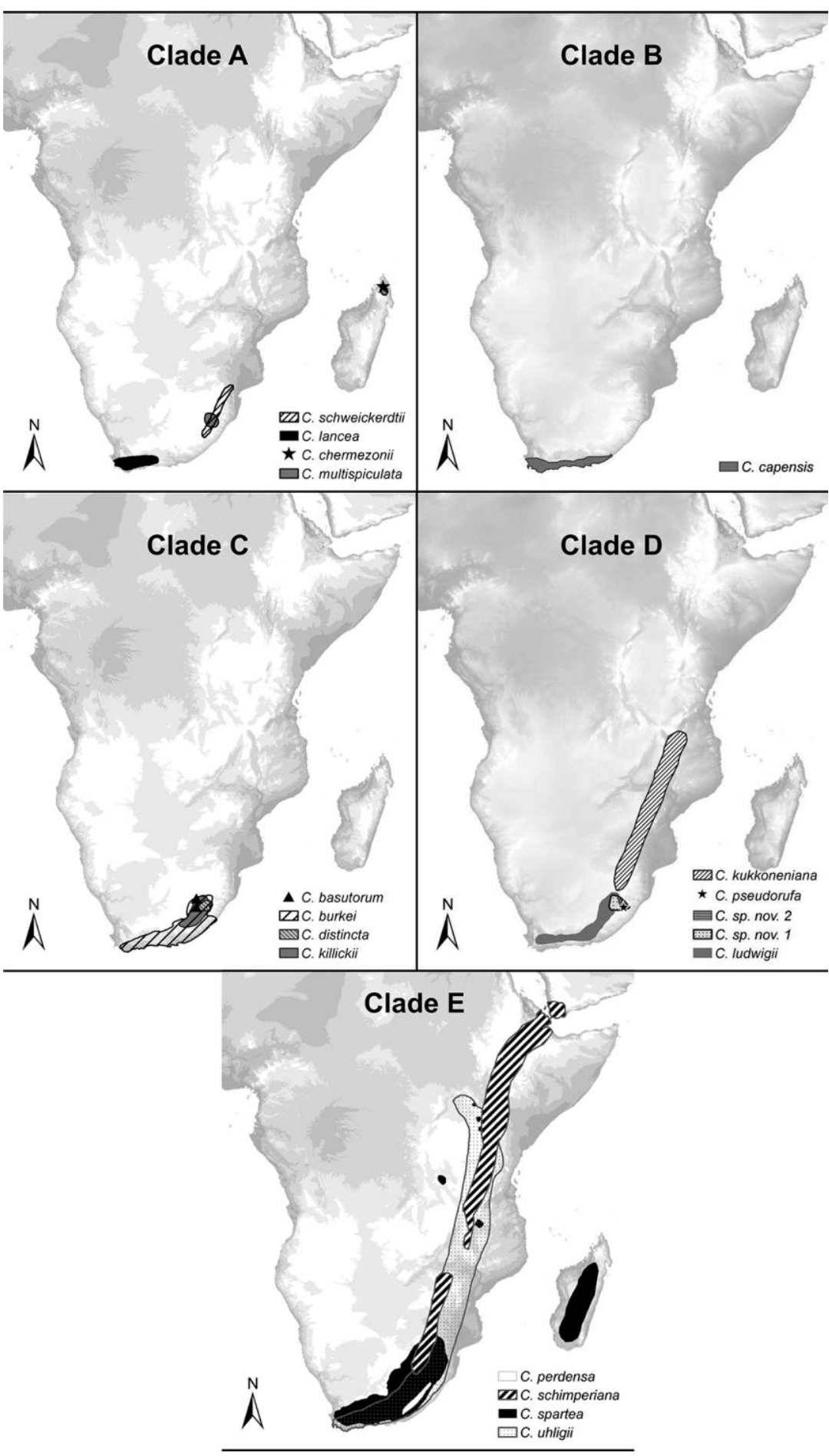

Fig. 1 Approximate distribution of species on each of the main clades in the former genus Schoenoxiphium. Based on Kukkonen (1983), field trips, and herbarium specimens examined. Elevation data are distributed by the Land Processes Distributed Active Archive Center, located at US Geological Survey Earth Resources Observation and Science Center, Sioux Falls, South Dakota (http://lpdaac.usgs.gov).

main phylogenetic structure of former genus Schoenoxiphium was well resolved, with five strongly supported main lineages.

Clade A (0.99 PP; 85\% BS; figs. 1, 2), sister to the remaining species of former genus Schoenoxiphium, was composed of three strongly supported monophyletic species: C. schweickerdtii (1 PP;
99\% BS), C. lancea (1 PP; 100\% BS), and C. multispiculata (1 PP; $100 \%$ BS). Carex capensis is retrieved as monophyletic in a strongly supported clade (clade B; $1 \mathrm{PP} ; 100 \% \mathrm{BS}$ ), sister to clades C, D, and E (figs. 1, 2). Clade C (1 PP; 99\% BS; figs. 1, 2 ), sister to clades $\mathrm{D}$ and $\mathrm{E}$, is formed by two lineages: one com- 
Table 1

Taxonomic Treatments of the Former Genus Schoenoxiphium

\begin{tabular}{|c|c|}
\hline Gordon-Gray (1995) & New circumscription in Carex (Global Carex Group 2015) \\
\hline S. altum Kukkonen ${ }^{\mathrm{a}}$ & C. capensis Thunb. \\
\hline S. ecklonii Nees ${ }^{\mathrm{a}}$ & C. capensis Thunb. \\
\hline S. basutorum Turrill & C. basutorum (Turrill) Luceño \& Martín-Bravo \\
\hline S. bracteosum Kukkonen & C. schimperiana Boeck. \\
\hline S. schimperianum (Boeckeler) C.B. Clarke & C. schimperiana Boeck. \\
\hline S. buchananii C.B. Clarke & C. kukkoneniana Luceño \& Martín-Bravo \\
\hline S. burkei C.B. Clarke & C. burkei (C.B. Clarke) Luceño \& Martín-Bravo \\
\hline S. burttii Kukkonen & C. pseudorufa Luceño \& Martín-Bravo \\
\hline S. caricoides C.B. Clarke & C. spartea Wahlenb. \\
\hline S. sparteum (Wahlenb.) C.B. Clarke & C. spartea Wahlenb. \\
\hline S. distinctum Kukkonen & C. distincta (Kukkonen) Luceño \& Martín-Bravo \\
\hline S. filiforme Kük. & C. killickii Nelmes \\
\hline S. strictum Kukkonen & C. killickii Nelmes \\
\hline S. gracile Cherm. ${ }^{a}$ & C. chermezonii Luceño \& Martín-Bravo \\
\hline S. lanceum (Thunb.) Kük. b & C. lancea (Thunb.) Baill. \\
\hline S. lehmanii (Nees) Steud. & C. uhligii K. Schum. ex C.B. Clarke \\
\hline S. ludwigii Hochst. & C. ludwigii (Hochst.) Luceño \& Martín-Bravo \\
\hline S. rufum Nees & C. ludwigii (Hochst.) Luceño \& Martín-Bravo \\
\hline S. madagascariense Cherm. & C. multispiculata Luceño \& Martín-Bravo \\
\hline S. perdensum Kukkonen & C. perdensa (Kukkonen) Luceño \& Martín-Bravo \\
\hline S. schweickerdtii Merxm. \& Podlech & C. schweickerdtii (Merxm. \& Podlech) Luceño \& Martín-Bravo \\
\hline
\end{tabular}

a Kukkonen (1986).

b Kukkonen (1983).

prises samples of C. burkei (1 PP; 93\% BS), and the other comprises samples of C. burkei as well as samples of C. basutorum, C. distincta, and C. killickii (1 PP; 93\% BS). Carex burkei appears as polyphyletic, whereas C. distincta and C. killickii are retrieved as paraphyletic. The single sample of C. basutorum included in our analyses does not allow us to test for the monophyly of the species. Clade D (1 PP; 99\% BS; figs. 1, 2), sister to clade E, is constituted by the monophyletic C. pseudorufa (1 PP; $100 \%$ BS) and another monophyletic clade comprising two tentative new species (hereafter Carex sp. nov. 1 and Carex sp. nov. 2; Márquez-Corro et al., forthcoming), C. kukkoneniana, C. ludwigii, and an unidentified species from Cape region similar to C. ludwigii (Carex sp.; fig. 2). Clade E (1 PP; 98\% BS) retrieved a monophyletic C. perdensa and a paraphyletic lineage constituted by C. schimperiana, C. spartea, and C. uhligii (figs. 1, 2). Sister group relationships of all clades were strongly supported except for clades D and $\mathrm{E}$.

\section{Discussion}

Our results show that former genus Schoenoxiphium is monophyletic and is sister to the clade containing sections Aciculares and Junciformes (fig. 2), confirming with strong support previous analyses (Waterway and Starr 2007; Starr and Ford 2009; Gehrke et al. 2010; Global Carex Group 2016). The species of sections Aciculares and Junciformes are distributed in South America and New Zealand, whereas former genus Schoenoxiphium has its center of diversity in South Africa. Phylogenetic relationships among species in the Schoenoxiphium clade herein reported are generally congruent with those obtained by Gehrke et al. (2010) based on ITS, $r p s 16$, and $t r n \mathrm{~L}-\mathrm{F}$. The former genus Schoenoxiphium has been recircumscribed within genus Carex
(Global Carex Group 2015; table 1). This group of species can be defined by a set of characters showed by most individuals: (i) compound inflorescences; (ii) scabrous or ciliate flattened raquilla, frequently leading to a male spike or a spike of spikelets, perigynia closed (utricles) to wide-mouthed (utricles with protruding male spikes or utriculiform cladoprophylls; JiménezMejías et al. 2016); and (iii) occasional occurrence of bisexual flowers (Gehrke et al. 2012). These morphological features of the former genus Schoenoxiphium and its strongly supported monophyly (fig. 2) deserve, in our opinion, taxonomic recognition at the sectional level (see below).

\section{Monophyly of Species within Section Schoenoxiphium}

In the strongly supported monophyletic clade A, we found species composed by big-sized plants: Carex schweickerdtii, C. lancea, and C. multispiculata (see table 1; fig. 2). All of them constitute well-supported monophyletic species. We suspect that the only unsampled species in our study, C. chermezonii, known only from the type locality in Madagascar (fig. 1), could be phylogenetically related to this group on the basis of morphological observations of the type specimen (M. Luceño, personal observation).

Carex capensis is retrieved as monophyletic in clade B (fig. 2). It displays a wide morphological variability, which has allowed the traditional recognition of two closely related species under the former genus Schoenoxiphium: S. ecklonii and S. altum (Kukkonen 1986). However, we have found that these species are not monophyletic and that diagnostic characters between them are inconstant (i.e., morphological intermediates are frequent; M. Luceño, personal observation). Therefore, we support the unification of both species, as has been stated by the 


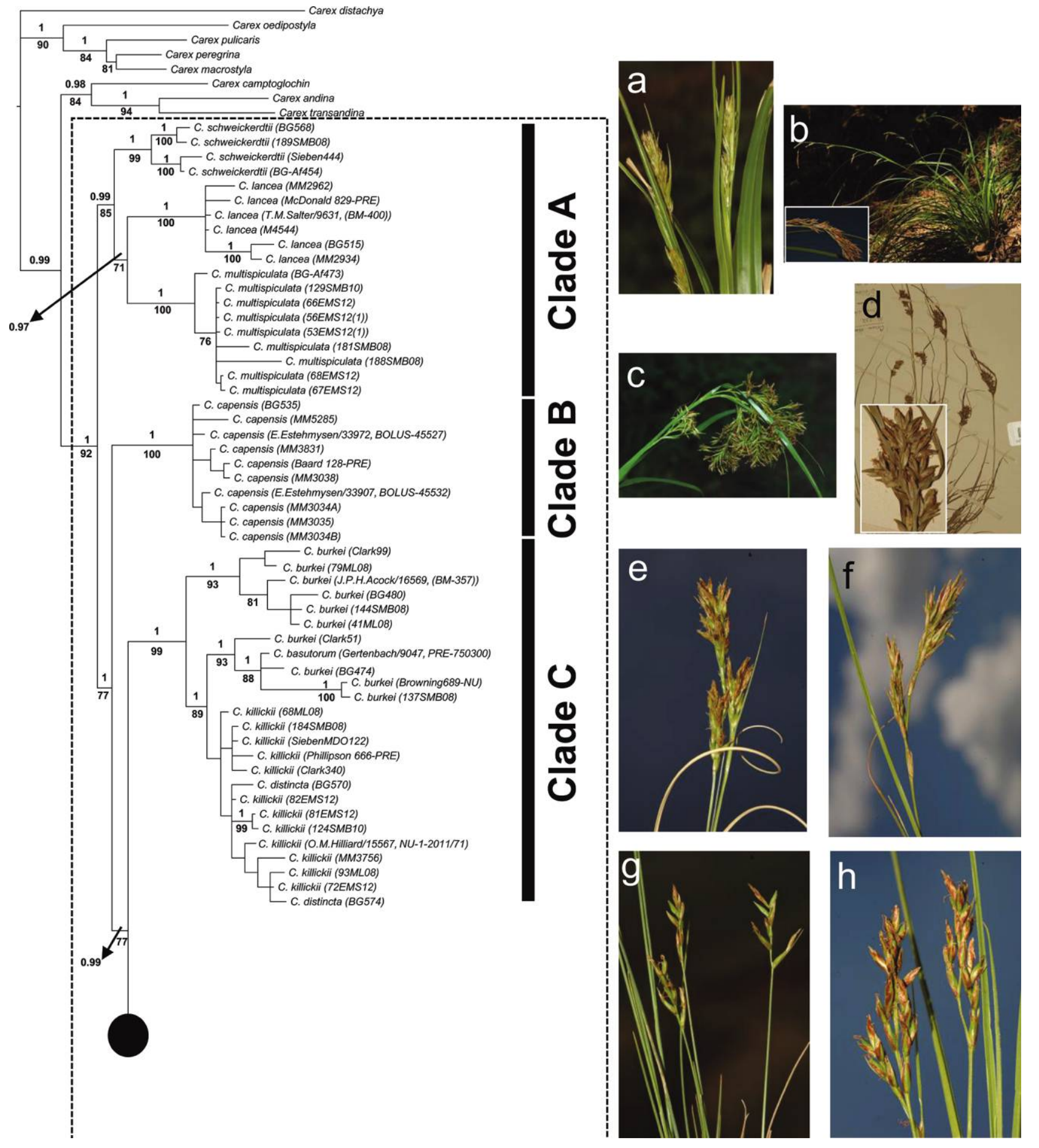

Fig. 2 Majority-rule consensus tree obtained in the Bayesian inference analysis of the combined matrix including ETS, ITS, matK, and $r p s 16$ DNA regions. Posterior probabilities (only if $>0.9$ ) are shown above branches, and maximum likelihood bootstrap support (if $>70 \%$ ) is shown below branches. Dashed line indicates circumscription of the Carex section Schoenoxiphium. Lateral bars indicate names of the clades. Photographs of species correspond to species in clade A (a, C. schweickerdtii; b, C. lancea; and c, C. multispiculata), clade B (d, C. capensis), clade C (e, C. burkei; f, C. basutorum; g, C. killickii; and h, C. distincta), clade D (i, C. pseudorufa; ;, C. ludwigii; k, C. kukkoneniana; l, Carex sp. nov. 2; and $m$, Carex sp. nov. 1), and clade E (n, C. perdensa; o, C. spartea; p, C. schimperiana; and q, C. ubligii). 



Fig. 2 (Continued) 
Global Carex Group (2015), until deeper studies may throw more light on the biosystematics of this group. Carex capensis has particular morphological characteristics that make it very distinctive from other species in the section: tubular cladoprophylls that are always present, sterile, and of second-to-last branching order and utricles that are 5-8 $\mathrm{mm}$ long with a rachilla protruding from the utricle apex, rarely bearing a male spikelet.

Carex basutorum, C. burkei, C. distincta, and C. killickii are placed in clade C. Carex burkei is retrieved as polyphyletic, whereas C. distincta and C. killicki are retrieved as paraphyletic (fig. 2), and we could not test the monophyly of C. basutorum, because we could include only one sample of this species. Nonetheless, their distinct morphology is reason to believe that they are different species (Global Carex Group 2015; fig. 2). The relatively small number of sequenced regions provided an insufficient number of informative characters to resolve species relationships within clade $\mathrm{C}$ (figs. 1, 2). All species of this clade co-occur in sympatry.

Similarly to what is found in clade C, most species in clades D and $\mathrm{E}$ are retrieved as para- or polyphyletic (figs. 1, 2), although they show congruent morphological characters that should keep them as different species until deeper molecular analyses explore these relationships. Most but not all species in this clade co-occur (fig. 1), which makes their taxonomic circumscription difficult. Within clade D, two new tentative species were found, which require additional morphological studies for their description. Additional studies might elucidate the contest found here between taxonomical studies and phylogenetic analyses in the Schoenoxiphium clade. In a framework of incipient speciation and/or hybridization (Gehrke et al. 2010), apparent monophyly of species may not be a general pattern. Next-generation sequencing appears as one of the best techniques to answer these interspecific phylogenetic questions (e.g., Massatti et al. 2016).

\section{Conclusions}

Our study resolves the backbone of the monophyletic Schoenoxiphium clade (former genus Schoenoxiphium). As discussed above, the former genus should be considered as a section within genus Carex.

$$
\begin{gathered}
\text { Carex sect. Schoenoxiphium Baillon, } \\
\text { Hist. Pl. (Baillon): 345, } 1894
\end{gathered}
$$

Type-C. rufa (Nees) Baillon, 1894, nom. illeg. [not C. rufa Lam., 1779] (=C. ludwigii (Hoscht.) Luceño \& Martín-Bravo, 2015)

$=$ Schoenoxiphium Nees in Linnaea 7: 581, 1832

$$
\begin{gathered}
\text { Type-Schoenoxiphium capense Nees, } 1832 \\
\text { (=Carex lancea (Thumb.) Baillon, 1894) }
\end{gathered}
$$

Five well-supported major lineages constitute the main structure of the section, but there are not yet clear morphological cuts between these clades. Finally, some internal relationships among species in the section are still unresolved and probably need the application of a next-generation sequencing approach to improve the phylogenetic resolution and understanding of the evolutionary history of the section at species level.

\section{Acknowledgments}

We thank all staff from herbaria BM, BOLUS, E, K, PRE, UPOS, and $\mathrm{Z}$ for giving us access to their collections and for providing plants. We are particularly grateful to J. C. Zamora for his help in the nomenclatural study. We also thank S. Guerra, J. M. Sierra, V. Pineda (UPO), M. D. Pirie (JGU), and A. M. Muasya (UCT) for assistance in plant collections and M. Míguez and F. J. Fernández (UPO) for technical support. The Spanish Ministry of Science and Technology supported this research through the project CGL2012-38744 and CGL201677401-P to M. Luceño (Principal Investigator), E. Maguilla, M. Escudero, S. Martín-Bravo, and T. Villaverde and an FPU fellowship (AP2012-2189) from the Spanish Government (Ministry of Education, Culture, and Sport) and a Synthesys grant (GB-TAF-2523) by the European Community Research Infrastructure Program to E. Maguilla.

\section{Appendix}

Studied material of Carex clade Schoenoxiphium (former genus Schoenoxiphium), related species, and outgroup, showing voucher information, herbarium (acronyms following Thiers 2015), country and province of collection, and GenBank accession numbers for ETS, ITS, matK, and rps 16.

Carex andina Phil., M. Luceño 24ML06 (UPOS-1837), Chile, RM Santiago Metropolitan, GU176151/-/-/GU176252. Carex basutorum (Turrill) Luceño \& Martín-Bravo, Gertenbach \& Groenewald 9047 (PRE-812904), South Africa, Free State, —I KY322260/KY322376/KY322317. Carex burkei (C.B.Clarke) Luceño \& Martín-Bravo, B. Gehrke et al. BG-Af474 (Z-39367), South Africa, Kwuazulu-Natal, GU176174/_/_/KY322352; B. Gehrke et al. BG-Af480 (Z-39369), South Africa, Free State, KY322171/_/_ C Clark et al. Clark51, South Africa (UPOS), KY322173/—/KY322382/KY322331; J.P.H. Acock 16569 (BM), South Africa, Cape Region, —/KY322269/KY322387/—; M. Luceño et al. 79ML08 (UPOS), South Africa, KwuazuluNatal, —_-_-KYY322294; M. Luceño et al. 41ML10 (UPOS), South Africa, Free State, KY322172/-/KY322365/ KY322296; S. Martín-Bravo et al. 137SMB08 (UPOS), South Africa, Free State, KY322174/_/_/KY322299; S. Martín-Bravo et al. 144SMB08 (UPOS), South Africa, Free State, _/_/_/KY322297; V.R. Clark et al. Clark99 (UPOS), South Africa, Cape Region, KY322170/_/_KY322334; Browning 689 (NU), AF285024/__/_. Carex camptoglochin V.I.Krecz., M. Luceño \& R. Álvarez 1906ML (UPOS-1831), Chile, Patagonia EU541856/_/_/EU541822; Molau et al. 2329 (GB), Ecuador, Chimborazo, -/AY244520/_- Carex capensis Thunb., Baard 128 (PRE), South Africa, Cape Province, AY242024/-/-/—; B. Gehrke et al. BG535 (UPOS), South Africa, Cape Region, KY322164/_/_/_; E. Estehmysen 33907 (BOLUS-45532), South 
Africa, Cape Region, KY322166/KY322253/KY322367/KY322300; E. Estehmysen 33972 (BOLUS-45527), South Africa, Cape Region, -/KY322265/_/_; M. Muasya et al. MM3034A, South Africa (UPOS) KY322167/_/_/KY322315; M. Muasya et al. MM3034B, South Africa (UPOS), KY322169/_/_/KY322338; M. Muasya et al. MM3035, South Africa (UPOS), KY322168/_/_/KY322318; M. Muasya et al. MM3038 (UPOS), South Africa, Cape Region, GU176182/_/_/_; M. Muasya et al. MM3831, South Africa (UPOS), KY322165/—/KY322386/KY322341; M. Muasya et al. MM5285, South Africa (UPOS), -1-/KYKY22323. Carex distachya Desf., M. Escudero et al. 65ME06 (UPOS-2266), Turkey, Manisa, GU176156/ -_-_GU176257. Carex distincta (Kukkonen) Luceño \& Martín-Bravo, B. Gehrke \& M. Pirie BG574 (UPOS-4390), South Africa, Kwuazulu-Natal, KY322188/_/_-; B. Gehrke \& M. Pirie BG570 (UPOS-4391), South Africa, Kwuazulu-Natal, KY322181/_/__. Carex killickii Nelmes, E. Maguilla et al. 72EMS12 (UPOS), South Africa, Kwuazulu-Natal, KY322187/ _/KY322385/KY322340; E. Maguilla et al. 80EMS12 (UPOS), South Africa, Kwuazulu-Natal, KY322183/KY322266/ KY322383/KY322332; E. Maguilla et al. 82EMS12 (UPOS), South Africa, Kwuazulu-Natal, KY322182/KY322255/ KY322369/KY322303; M. Luceño et al. 68ML08 (UPOS), South Africa, Free State, KY322175/—/—_; M. Luceño et al. 93ML08 (UPOS), South Africa, Kwuazulu-Natal, KY322186/_-__; M. Muasya et al. MM3756, South Africa (UPOS), KY322185/_/_/KY322291; Phillipson et al. 666 (PRE), South Africa, Eastern Cape, AY242020/_/_/; Sieben, MDO122, South Africa (UPOS), KY322179/_/__; S. Martín-Bravo et al. 124SMB10 (UPOS), South Africa, Free State, KY322184/ _/__; S. Martín-Bravo et al. 184SMB08 (UPOS), South Africa, Kwuazulu-Natal, KY322176/_/_/_; V.R. Clark \& T. Te Water Naude Clark340 (UPOS), South Africa, Cape Region, KY322180/_/_/KY322309; O.M.Hilliard, 15567, South Africa, Bamboo Mt., (NU-1-2011/71), _/_-KYY352040. Carex kukkoneniana Luceño \& Martín-Bravo, B. Gehrke \& H.I. Patel BG-Af321 (Z-39364), Malawi, Northern Region, KY322220/—/KY322362/—; F. Mbago et al. BG-Af338 (Z-39363), Tanzania, Iringa District, EU288650/___ Carex lancea (Thunb.) Baill., B. Gehrke et al. BG515 (BOL), South Africa, Western Cape, GU176185/_/__; McDonald 829 (PRE), South Africa, Cape Province, AY242028/_/_-; Muasya et al. MM2934, South Africa (UPOS), KY322161/_/_/KY322307; M. Muasya et al. MM2962, South Africa (UPOS), KY322158/—/KY322389/ KY322343; M. Muasya et al. MM4544, South Africa (UPOS), KY322160/_/KY322393/—; T.M. Salter 9631 (BM), South Africa, Cape Region, KY322159/KY322273/KY322392/KY322348. Carex ludwigii (Hochst.) Luceño \& Martín-Bravo, B. Gehrke \& M. Pirie BG572 (UPOS-4393), South Africa, Kwazulu-Natal, KY322197/_/_/KY322290; E. Maguilla et al. 64EMS12 (UPOS), South Africa, Kwuazulu-Natal, KY322192/KY322246/KY322357/KY322280; E. Maguilla et al. 78EMS12a (UPOS), South Africa, Kwuazulu-Natal, KY322193/—/KY322358/KY322281; M. Luceño et al. 65ML08 (UPOS-3616), South Africa, South Africa, Free State, KY322195/_/_-; M. Luceño et al. 106ML08 (UPOS), South Africa, Kwazulu-Natal, KY322194/_/_/KY322287; S. Martín-Bravo et al. 147SMB10 (UPOS), South Africa, Kwazulu-Natal, —_/_/KY322289; S. Martín-Bravo et al. 159SMB10 (UPOS), South Africa, Kwazulu-Natal, KY322196/_/_/KY322288; S. Martín-Bravo et al. 162 SMB10 (UPOS), South Africa, Kwuazulu-Natal, _/_/KYK322282. Carex macrostyla Lapeyr., J.A. Alejandre \& M.J. Escalante s.n. (UPOS-2667), Spain, Burgos, GU176157/_/_/GU176258. Carex multispiculata Luceño \& Martín-Bravo, B. Gehrke et al. BG-Af473 (Z-39370), South Africa, Kwuazulu-Natal, KY322162/_/_/KY322336; E. Maguilla et al. 53EMS12 (1) (UPOS), South Africa, Kwuazulu-Natal, _/KY322254/KY322368/KY322301; E. Maguilla et al. 56EMS12(1) (UPOS), South Africa, Kwuazulu-Natal, _/KY322250/KY322363/KY322250; E. Maguilla et al. 66EMS12 (UPOS), South Africa, KwuazuluNatal, KY322163/KY322274/KY322350/KY322394; E. Maguilla et al. 67EMS12 (UPOS), South Africa, Kwuazulu-Natal, —/KY322271/KY322390/KY322346; E. Maguilla et al. 68EMS12 (UPOS), South Africa, Kwuazulu-Natal, —/KY322262/ KY322378/KY322321; S. Martín-Bravo et al. 181SMB08 (UPOS), South Africa, Kwuazulu-Natal, GU176197_/_/_; S. MartínBravo et al. 188SMB08 (UPOS), South Africa, Kwuazulu-Natal, GU176206/___-; S. Martín-Bravo et al. 129 SMB10 (UPOS), South Africa, Kwuazulu-Natal —/KY322257/KY322371/KY322305. Carex oedipostyla Duval-Jouve, P. Jiménez-Mejías \& M. Luceño 35PJM04 (UPOS-1779), Spain, Cádiz, GU1761160/_/_/GU176260. Carex perdensa (Kukkonen) Luceño \& Martín-Bravo, E. Maguilla et al. 73EMS12 (UPOS), South Africa, Kwazulu-Natal, KY322215/KY322259/KY322375/KY322316; E. Maguilla et al. 74EMS12a (UPOS), South Africa, Kwazulu-Natal, —/KY322264/KY322380/KY322326; E. Maguilla et al. 74EMS12b (UPOS), South Africa, Kwazulu-Natal, KY322213/KY322267/KY322384/KY322333; E. Maguilla et al. 74EMS12c (UPOS), South Africa, Kwazulu-Natal, KY322214/_/__; M. Luceño et al. 98ML08 (UPOS), South Africa, Kwazulu-Natal, KY322211/_/KY322374/ KY322313; M. Luceño et al. 120ML08 (UPOS), South Africa, Kwazulu-Natal, GU176209/_/__; M. Muasya et al. MM3719 (UPOS), South Africa (UPOS), KY322212/_/_/KY322328. Carex peregrina Link, H. Schaefer s.n. (BM-2008/750), Portugal, —-/HM850848/—; M. Luceño \& P. Vargas, s.n. (UPOS-142), Portugal, Madeira, GU176162/_/_/GU176262. Carex pseudorufa Luceño \& Martín-Bravo, B. Gehrke \& M. Pirie BG567 (UPOS-4396), South Africa, Kwazulu-Natal, KY322191/_/KY322355/ KY322278; E. Maguilla et al. 59EMS12 (UPOS), South Africa, Kwuazulu-Natal, KY322189/_/KY322354/KY322277; E. Maguilla et al. 85EMS12 (UPOS), South Africa, Kwuazulu-Natal, KY322190/KY322245/KY322356/KY322279. Carex pulicaris L., M. Luceño 5806ML (UPOS-1970), Iceland, Southern Peninsula, GU176163/_/_/EU541829; Starr \& Scott 98001 (FHO), United Kingdom, England, _/AY242019/_/—; Rich et al. s.n. (NMW6259), United Kingdom, Breconshire, —/JN894931/-. Carex schimperiana Boeckeler, B. Gehrke \& M. Muasya BG-Af160 (Z-39365), Kenya, Saiwa Samp National Park, EU288648/—I_/—; B. Gehrke et al. BG-Af193 (Z-39359), Ethiopia, Menangesha Suba State Forest, EU288651/_/_-; B. Gehrke et al. BG-Af467 (Z, ZT), South Africa, Kwazulu-Natal, EU288644/_/GU176144/_/; Clark133, South Africa (UPOS), KY322230/KY322270/ KY322388/KY322342; E. Maguilla et al. 46EMS12 (UPOS), South Africa, Kwazulu-Natal, KY322234/KY322251/KY322364/ KY322295; E. Maguilla et al. 69EMS12 (UPOS), South Africa, Kwazulu-Natal, KY322242/KY322256/KY322370/KY322304; E. Maguilla et al. 84EMS12 (UPOS), South Africa, Kwazulu-Natal, KY322235/KY322252/KY322366/KY322298; Sieben, MDO622, South Africa (UPOS) KY352041/_//-; M. Luceño et al. 117ML08 (UPOS), South Africa, Kwazulu-Natal, 
KY322236/_/_/KY322345; M. Muasya et al. MM3644, South Africa (UPOS), KY322234/_/_/KY322344; M. Muasya et al. MM4913, South Africa (UPOS), KY322238/_/_/KY322339; M. Muasya MM5176 South Africa (UPOS), KY322228/ _/_/KY322324; M. Muasya et al. MM5186, South Africa (UPOS), KY322229/_/_/KY322330; S. Martín-Bravo et al. 146SMB10 (UPOS), South Africa, Kwazulu-Natal, KY322239/_/_/KY322329; S. Martín-Bravo et al. 154SMB10 (UPOS), South Africa, Kwazulu-Natal, KY322241/_/_KY322380. Carex schweickerdtii (Merxm. \& Podlech) Luceño \& Martín-Bravo, B. Gehrke et al. BG-Af454 (Z-39358), South Africa, Kwazulu-Natal, KY322157/_/KY322396/—; B. Gehrke \& M. Pirie BG568 (UPOS), South Africa, Kwazulu-Natal, KY322154/_KY322373/KY322311; Sieben, Sieben444; South Africa (UPOS), KY322156/—/KY322381/ KY322327; S. Martín-Bravo et al. 189SMB08 (UPOS), South Africa, Kwazulu-Natal, KY322155/_/KY322372/KY322310. Carex sp., Sonnenberg, Sonnenberg 29, South Africa, eastern Cape (UN-1-2011/165), KY322199/KY322268/_/KY322337; McKenzie et al. 129a (UPOS), South Africa, Cape Region, KY322244/___/KY322353; McKenzie et al. 129b (UPOS), South Africa, Cape Region, KY322198/_/_/KY322322. Carex spartea Wahlenb., B. Gehrke BG-Af275 (Z-39356), Madagascar, Fianarantsoa, KY322218/ _/_- B. Gehrke BG-Af432 (Z-39360), South Africa, Eastern Cape, KY322223/—_- _ B. Gehrke, BG-Af451 (Z-39371), South Africa, Kwazulu-Natal, EU288642/_/_- E. Maguilla et al. 45EMS12 (UPOS), South Africa, Kwazulu-Natal, KY322226/ _/__; M. Luceño et al. 66ML08 (UPOS), South Africa, Free State, KY322222/KY322261/_/KY322320; E. Maguilla et al. 70EMS12c (UPOS), South Africa, Kwazulu-Natal, KY322224/KY322272/KY322347/KY322391; E. Maguilla et al. 70EMS12d (UPOS), South Africa, Kwazulu-Natal, KY322225/KY322275/KY322395/KY322351; M. Muasya et al. MM3720, South Africa (UPOS), KY322227/__/KY322314; M. Muasya et al. MM3775, South Africa (UPOS), _/__/KY322335; M. Muasya et al. MM3784, South Africa (UPOS), KY322219/_/_/KY322306; M. Muasya et al. MM4900a (UPOS), South Africa, Kwazulu-Natal, KY322240/_/KYK322312; M. Muasya et al. MM4900b (UPOS), South Africa, Kwazulu-Natal, KY322216/—/_; M. Muasya MM4909 (UPOS), South Africa, KY322221/_/__; M. Muasya et al. MM4924 (UPOS), South Africa, KY322243/—/—/—; S. Martín-Bravo et al. 153SMB10 (UPOS), South Africa, Kwazulu-Natal, KY322220/_/_/KY322302; M. Muasya et al. MM129_2010; South Africa (UPOS), KY322217/_/__. Carex transandina G.A. Wheeler, M. Luceño \& R. Álvarez 12ML06 (UPOS1824), Chile, Tierra del Fuego, GU176166/_/_/GU176265. Carex ubligii K. Schum. ex C.B. Clarke, E. Maguilla et al. 51EMS12 (UPOS), South Africa, Kwazulu-Natal, KY322178/KY322263/KY322379/KY322325; J.E. Burrows 8691 (PRE841896), South Africa, Mpumalanga, KY322231/KY322258/___; Killick \& Marais 2029 (BM), South Africa, Kwazulu-Natal, —/KY322276/_/_; M. Muasya et al. MM3864 (UPOS), South Africa, KY322233/_/KY322377/KY322319; P. Vargas et al. 463PV00 (UPOS), South Africa, KY322232/_/_/KY322349; Williams 1007 (PRE), South Africa, Kwazulu-Natal, AY242026/ _/___; 418PMM07 (UPOS), Kenya, KY322177/_/_/KY322293; Carex sp. nov. 1, E. Maguilla et al. 77EMS12 (UPOS-8503), South Africa, Kwazulu-Natal, KY322206/KY322247/KY322359/-; M. Luceño et al. 94ML08 (UPOS-3626), South Africa, Kwazulu-Natal, KY322205/_/_/KY322283; M. Luceño et al. 101ML08 (UPOS-3591), South Africa, Kwazulu-Natal, KY322207/_/__; M. Luceño et al. 101ML08bis (UPOS-3592), South Africa, Kwazulu-Natal, KY322209/—/_/_; M. Luceño et al. 107ML08 (UPOS-3594), South Africa, Kwazulu-Natal, KY322204/_/_-; S. Martín-Bravo et al. 125 SMB10 (UPOS8504), South Africa, Free State, KY322208/____; S. Martín-Bravo et al. 126SMB10 (UPOS-8525), South Africa, Free State, KY322203/_/__; S. Martín-Bravo et al. 141SMB10 (UPOS), South Africa, Kwazulu-Natal, KY322210/—/_- ;. Martín-Bravo et al. 143SMB08 (UPOS-3601), South Africa, Free State, KY322202/_/_- Carex sp. nov. 2, E. Maguilla et al. 76 EMS12 (UPOS), South Africa, Kwazulu-Natal, KY322201/KY322248/KY322360/KY322284; M. Luceño et al. 92ML08 (UPOS-3624), South Africa, Kwazulu-Natal, _/_/_KY322286; S. Martín-Bravo et al. 145SMB10 (UPOS-8501), South Africa, Kwazulu-Natal, - /KY322249/KY322361/KY322285.

\section{Literature Cited}

Blattner FR 1999 Direct amplification of the entire ITS region from poorly preserved plant material using recombinant PCR. Biotechniques 27:1180-1186.

Edgar RC 2004 MUSCLE: multiple sequence alignment with high accuracy and high throughput. Nucleic Acids Res 32:1792-1797.

Ford CS, KL Ayres, N Toomey, N Haider, JVA Stahl, LJ Kelly, N Wikström, et al 2009 Selection of candidate coding DNA barcoding regions for use on land plants. Bot I Linn Soc 159:1-11.

Gehrke B, S Martin-Bravo, M Muasya, M Luceño 2010 Monophyly, phylogenetic position and the role of hybridization in Schoenoxiphium Nees (Cariceae, Cyperaceae). Mol Phylogenet Evol 56:380-392.

Gehrke B, A Vrijdaghs, E Smets, AM Muasya 2012 Unisexual flowers as a robust synapomorphy in Cariceae (Cyperaceae)? evidence for bisexual flowers in Schoenoxiphium. S Afri _ Bot 78:150-158.

Global Carex Group 2015 Making Carex monophyletic (Cyperaceae, tribe Cariceae): a new broader circumscription. Bot I Linn Soc 179: $1-42$.

2016 Megaphylogenetic specimen-level approaches to the Carex (Cyperaceae) phylogeny using ITS, ETS, and matK sequences: implications for classification. Syst Bot 41:500-518.
Goetghebeur P 1998 Cyperaceae. Pages 141-190 in K Kubitzki, ed. The families and genera of vascular plants. Vol 4. Springer, Berlin. Gordon-Gray KD 1995 Schoenoxiphium. Pages 162-171 in Cyperaceae in Natal. Strelitzia 2. National Botanical Institute, Pretoria, South Africa.

Huelsenbeck JP, F Ronquist 2001 MrBayes: Bayesian inference of phylogeny. I Bioinform 17:754-755.

Jiménez-Mejías P, M Luceño, KL Wilson, MJ Waterway, EH Roalson 2016 Clarification of the use of the terms perigynium and utricle in Carex L. (Cyperaceae). Syst Bot 41:519-528.

Kukkonen I 1983 The genus Schoenoxiphium (Cyperaceae): a preliminary account. Bothalia 14:819-823.

1986 Schoenoxiphium. Pages 345-405 in OM Hilliard, BL Burtt, eds. Notes of some plants of Africa chiefly from Natal. Vol XIII. Royal Botanic Garden, Edinburgh, Scotland.

Levyns MR 1945 A comparative study of the inflorescence in four species of Schoenoxiphium and its significance in relation to Carex and its allies. S Afr J Bot 11:79-89.

Márquez-Corro JI, E Maguilla, T Villaverde, S Martín-Bravo, M Luceño Forthcoming Two new species in Carex section Schoenoxiphium (Cyperaceae) from South Africa. Phytotaxa. 
Massatti R, AA Reznicek, LL Knowles 2016 Utilizing RADseq data for phylogenetic analysis of challenging taxonomic groups: a case study in Carex sect. Racemosae. Am I Bot 103:337-347.

Muasya AM, DA Simpson, GA Verboom, P Goetghebeur, RFC Naczi, MW Chase, E Smets 2008 Phylogeny of Cyperaceae based on DNA sequence data: current progress and future prospects. Bot Rev 75: $2-21$.

Posada D 2008 jModelTest: phylogenetic model averaging. Mol Biol Evol 25:1253-1256.

Roalson EH, JT Columbus, EA Friar 2001 Phylogenetic relationships in Cariceae (Cyperaceae) based on ITS (nrDNA) and $\operatorname{trn}$ T-L-F (cpDNA) region sequences: assessment of subgeneric and sectional relationships in Carex with emphasis on section Acrocystis. Syst Bot 26:318-341.

Shaw J, EB Lickey, JT Beck, SB Farmer, W Liu, J Miller, KC Siripun, CT Winder, EE Schilling, RL Small 2005 The tortoise and the hare II: relative utility of 21 noncoding chloroplast DNA sequences for phylogenetic analysis. Am I Bot 92:142-166.

Stamatakis A 2006 RAxML-VI-HPC: maximum likelihood-based phylogenetic analyses with thousands of taxa and mixed models. L Bioinform 22:2688-2690.

Starr JR, RJ Bayer, BA Ford 1999 The phylogenetic position of Carex section Phyllostachys and its implications for phylogeny and subgeneric circumscription in Carex (Cyperaceae). Am I Bot 86:563577.
Starr JR, BA Ford 2009 Phylogeny and evolution in Cariceae (Cyperaceae): current knowledge and future directions. Bot Rev 75: 110-137.

Starr JR, SA Harris, DA Simpson 2003 Potential of the 5 and 3 ends of intergenic spacer (IGS) of rDNA in the Cyperaceae: new sequences for lower-level phylogenies in sedges with an example from Uncinia Pers. Int I Plant Sci 164:213-227.

Thiers B 2017 Index herbariorum: a global directly of public herbaria and associated staff. New York Botanical Garden's Virtual Herbarium, http://sweetgum.nybg.org/ih/.

Timonen T 1989 Synflorescence structure of Schoenoxiphium lanceum (Cyperaceae). Ann Bot Fenn 26:319-342.

Waterway MJ, T Hoshino, T Masaki 2009 Phylogeny, species richness, and ecological specialization in Cyperaceae tribe Cariceae. Bot Rev 75:138-159.

Waterway MJ, JR Starr 2007 Phylogenetic relationships in tribe Cariceae (Cyperaceae) based on nested analyses of four molecular data sets. Aliso 23:165-192.

White TJ, T Bruns, S Lee, J Taylor 1990 Amplification and direct sequencing of fungal ribosomal RNA genes for phylogenetics. Pages 315322 in M Innis, D Gelfand, J Sninsky, TJ White, eds. PCR protocols: a guide to methods and amplifications. Academic Press, San Diego, CA.

Yen AC, RG Olmstead 2000 Molecular systematics of Cyperaceae tribe Cariceae based on two chloroplast DNA regions: $n d h \mathrm{~F}$ and $t r n \mathrm{~L}$ intron-intergenic spacer. Syst Bot 25:479-494. 